\title{
Practical laboratory considerations amidst the COVID-19 outbreak: early experience from Singapore
}

\author{
Shaun S Tan (1), Benedict Yan, Sharon Saw, Chun Kiat Lee, Ai Teng Chong, \\ Roland Jureen, Sunil Sethi
}

National University Hospital, Singapore

\section{Correspondence to}

Dr Shaun S Tan, National University Hospital, Singapore 119074, Singapore; shaun_sy_ tan@nuhs.edu.sg

Received 8 March 2020 Revised 10 March 2020 Accepted 11 March 2020 Published Online First 20 March 2020
A) Check for updates

(C) Author(s) (or their employer(s)) 2021. No commercial re-use. See rights and permissions. Published by BMJ.

To cite: Tan SS, Yan B, Saw S, et al. J Clin Pathol 2021;74:257-260.

\begin{abstract}
The coronavirus disease 2019 (COVID-19) is a zoonotic viral infection originating from Wuhan, China in December 2019. The World Health Organization has classified this pandemic as a global health emergency due to its virulent nature of transmission, which may lead to acute respiratory distress syndrome. Singapore's health ministry has responded with enhanced surveillance of COVID-19 for all suspected pneumonia cases, further increasing the volume of testing via real-time reverse transcription PCR, as well as samples necessitating stringent infectious control. Collectively, this has implications on the total testing process, laboratory operations and its personnel due to biosafety concerns. Turnaround time for routine testing may also be affected. The aim of this article is to present our tertiary institution's early experience with managing this emerging crisis and offer practical considerations for the preanalytical, analytical and postanalytical phases of laboratory testing in this cohort of patients.
\end{abstract}

\section{INTRODUCTION}

A group of mysterious pneumonia cases with unknown aetiology linked to the Huanan seafood market in Wuhan, China occurred in December 2019. Patients often presented with fever, dyspnoea, chest discomfort, coryza and cough, but several progressed to require intensive care respiratory support. ${ }^{1}$ The pathogen implicated has now been identified as an entity within the family of betacoronavirus, the disease it causes being called coronavirus disease 2019 (COVID-19). The official nomenclature of the virus also evolved to become the severe acute respiratory syndrome coronavirus 2 (SARS-CoV-2) according to the International Committee on Taxonomy of Viruses. ${ }^{2}$ Li et al ${ }^{3}$ have categorically described human-to-human transmission by COVID-19 likely secondary to respiratory droplets and environmental contamination through fomites. In a matter of few months, the virulence of COVID-19 resulted in a global outbreak of disease, and the WHO has declared this as a public health emergency.

Despite its small geographical size, outside of China, Singapore initially had the greatest number of confirmed COVID-19, with 81 patients as of 18 February $2020 .^{4}$ In part, these numbers may be attributed to our health ministry's expedient ring-fencing of the outbreak by increased testing of all suspect cases meeting the WHO case definition through the National Public Health Laboratory, enhanced surveillance for all patients with pneumonia and contact tracing of the confirmed cases within their clusters. We have also established the real-time reverse transcription PCR (rRTPCR) test for molecular diagnosis of COVID-19 by targeting the 85 base pair region of the open reading frame $1 \mathrm{ab}$ gene and 65 base pair region of the nucleocapsid gene, based on sequence alignment to SARS-CoV-2 genome. This has been implemented in our tertiary public hospitals to ensure a more rapid turnaround time.

Due to the nature of its transmissibility, hospital healthcare workers and laboratory staff face uncertainties with this emerging infection. There are fears of contracting the illness, in addition to biosafety and environmental concerns. Operationally, turnaround times for routine tests may be affected in view of manpower constraints. The aim of this article is to present our tertiary institution's firsthand experience in managing the outbreak in Singapore. We aim to succinctly describe the important operational, preanalytical, analytical and postanalytical strategies to ensure an infectious pathogen such as SARS-CoV-2 is safely dealt with within a laboratory setting.

\section{LABORATORY AND OPERATIONAL PREPAREDNESS}

A pandemic situation occurs in the event of an emerging pathogen spreading easily through the general population where there is no inherent immunity. To assess its severity to public health, Singapore adopts the 'Disease Outbreak Response System Condition' (DORSCON) in order to systematically guide the need for containment, contact tracing and screening based on the risks of spread. ${ }^{5}$ During this period of COVID-19 outbreak, our DORSCON was raised to 'Orange' status, which implied that the disease is severe and could spread widely from person to person but was still being contained. ${ }^{6}$ Lee et $a l^{7}$ have categorically demonstrated the utility of several public health measures which would mitigate spread of a pandemic such as influenza, and this would also be applicable to a COVID-19 outbreak. Operationally within hospitals and laboratories, team segregation and social distancing would be advocated. This will allow lower potential for cross-infection between the teams, but at the same time allow execution of their duties independently. Examples should include staggered meal times and deferment of large group gathering. Simple temperature taking, twice a day, is advised to allow early identification of acute respiratory infection symptoms. Should someone 
in the team be infected with COVID-19, quarantine measures would need to be initiated for all close contacts.

Business continuity and contingency plans with other departments and laboratories should be reinforced in the event that all teams have fallen ill or are quarantined. In terms of human resource planning, non-essential overseas annual leave to hotspot countries should be suspended until transmission has plateaued or reached a trough. The laboratory manager should factor in burn-out and psychological fatigue from segregated teams and the increased workload anticipated. During this period, education and training may still continue in the spirit of learning, but it would be recommended that this be conducted via remote video conferencing services with cloud computing, for example using Zoom.

\section{PREANALYTICAL CONSIDERATIONS}

In order to provide safe infection control practices in the midst of a COVID-19 outbreak, a robust transportation protocol for samples should be designed. Based on the WHO guidelines, ${ }^{8}$ all specimens (swabs, body fluids, blood, faeces) must be considered potentially infectious, and appropriate personal protective equipment (PPE) must be donned while obtaining samples from the suspected patient or manipulating such samples. Typically, this includes a disposable gown, gloves, cap, shoe cover, protective eyewear and an N95 respirator mask. A powered airpurifying respirator should also be considered in the event that aerosol-generating procedures such as bronchoscopy, endotracheal intubation or centrifugation are performed. With respect to transportation, we recommend that specimens should be tightly capped and transported to the central laboratory in biohazard zip-lock bags, within a leak-proof cryobox with a clearly visible biohazard label (figure 1). Specimens should be hand-delivered and not sent via pneumatic tube because this increases the risk of samples being lost in transit or the occurrence of spillages. Adequate specimen processing and storage spaces should be preemptively dedicated to managing suspect COVID-19 specimens lest the operational staff be overwhelmed from a sudden influx of specimens for testing.

In our institution, we faced a surge of demand of cryoboxes during the outbreak, and our laboratory received a great number of cryoboxes at any one period of time. To circumvent requiring the nurses having to telephone the laboratory for every single request, we devised a list of 'urgent samples' where an urgent label was placed on the box in order to prioritise them (table 1).

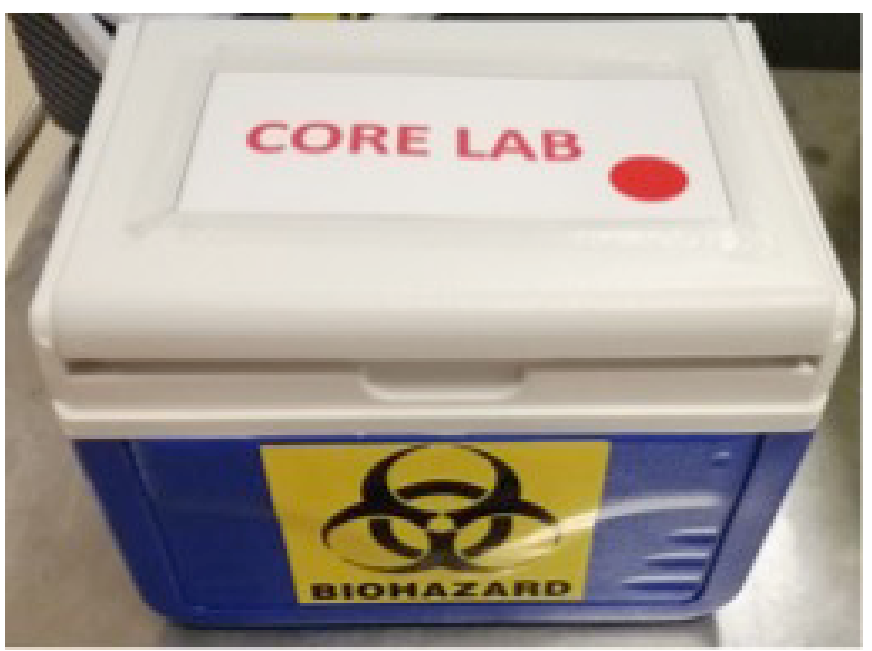

Figure 1 Laboratory cryobox.

\begin{tabular}{|c|c|}
\hline \multirow[t]{7}{*}{ Chemistry } & Lactate. \\
\hline & Arterial blood gas. \\
\hline & lonised calcium. \\
\hline & Ammonia. \\
\hline & Adrenocorticotropic hormone. \\
\hline & Beta-hydroxybutyrate. \\
\hline & Bicarbonate. \\
\hline \multirow[t]{2}{*}{ Microbiology } & Cerebrospinal fluid samples. \\
\hline & Influenza/respiratory syncytial virus PCR. \\
\hline Haematology & $\begin{array}{l}\text { Activated partial thromboplastin time for patients on } \\
\text { heparin therapy. }\end{array}$ \\
\hline
\end{tabular}

These are primarily for samples that may have an artefactual increase in results, for example lactate or arterial blood gas if they were not expediently processed. For samples which are required to be transported to a secondary laboratory, one must also consider the WHO and International Air Transport Association guidelines ${ }^{9}$ for transport of infectious samples. To this end, it is recommended that a 'triple packaging system' be used to contain an infectious substance, which consists of the primary receptacle, a second watertight and leak-proof packaging to protect the primary receptacle, and a third outer layer of packaging used to prevent physical damage to the secondary packaging while in transit.

Importantly, timely communication between both hospital healthcare workers and laboratory professionals is paramount to ensure mutual understanding and collaboration. These may include preparing a memo to inform laboratory users about potential delay in turnaround time for tests in view of increased workload, certain test menu limitations, and providing a 24-7 phone service and laboratory email address for helping with queries. Our institution recommends a sterile container for lower respiratory tract specimens, for example sputum, endotracheal tube aspirate and bronchoalveolar lavage. Universal transport medium (Copan Diagnostics, Murrieta, California) is used for nasopharyngeal and oropharyngeal swabs, where the swab has to be immersed fully within $3 \mathrm{~mL}$ of fluid and capped tightly to prevent leakage. All samples need to be labelled appropriately, and such sample guides should be visible to all ward and emergency department users. We also recommend a fast transition from manual paper request to electronic request for COVID-19 molecular testing in order to minimise the issue of unlabelled specimens or specimens without test orders.

\section{ANALYTICAL CONCERNS}

Analysis of suspected COVID-19 samples is challenging for a number of reasons. Samples from such patients may appear incognito and unidentified to the laboratory, and as such pose as an occupational health risk to medical technologists during analysis. Despite demands for total laboratory automation, due to the complexity of modern laboratory medicine, procurement issues and a broad test menu, a multitude of analysers commonly exist in any one laboratory. The various manual touch-points outside of the laboratory automation system may potentiate a risk of contamination or transmission as the system is not 'selfcontained'. These may include processes such as sample dilutions, secondary aliquoting, performing cytospin centrifugation and vortexing procedures.

In our institution, we recommend processing all suspect or confirmed COVID-19 patient samples within a class 2 biological safety cabinet (BSC), in full PPE attire as described above. 
Table 2 'At a glance' summary of important laboratory considerations during COVID-19 outbreak

\begin{tabular}{|c|c|c|}
\hline & Issues & Suggested solutions \\
\hline $\begin{array}{l}\text { Operational } \\
\text { preparedness }\end{array}$ & Ease of transmissibility of SARS-CoV-2 via respiratory droplets. & $\begin{array}{l}\text { Team segregation, social distancing, for example, staggered meal timings } \\
\text { and deferment of large group gatherings. } \\
\text { Reinforcement of business continuity and contingency plans with other } \\
\text { departments. } \\
\text { Quarantine measures for staff who are unwell. } \\
\text { Use of web-based remote learning platforms for training or conferencing. }\end{array}$ \\
\hline Preanalytical phase & $\begin{array}{l}\text { Potential occupational hazards handling COVID-19 patient samples. } \\
\text { Leakage of samples in containers or during transit. }\end{array}$ & $\begin{array}{l}\text { Full personal protective equipment used while processing such samples. } \\
\text { Samples preferably processed in a class } 2 \text { biological safety cabinet. } \\
\text { Transport of suspected or confirmed COVID-19 patient samples to be } \\
\text { within a leak-proof cryobox. } \\
\text { No pneumatic tubes to be used. } \\
\text { Prioritise urgent samples, that is, lactate or arterial blood gas, within the } \\
\text { cryobox. }\end{array}$ \\
\hline Analytical phase & $\begin{array}{l}\text { Manual processes may result in contamination of surfaces, that is, } \\
\text { centrifugation of samples with aerosol generation and manual pipetting } \\
\text { resulting in fomites. } \\
\text { Samples not identified as COVID-19 may arrive in the laboratory } \\
\text { incognito. }\end{array}$ & $\begin{array}{l}\text { Conduct a full risk assessment of all analytical processes in the } \\
\text { laboratory. } \\
\text { Full decontamination must be performed using an Environmental } \\
\text { protection agency-approved solution against the SARS-CoV- } 2 \text {, for } \\
\text { example, } 70 \% \text { alcohol or } 0.1 \% \text { sodium hypochlorite solution. }\end{array}$ \\
\hline Postanalytical phase & Transmission and reporting of results securely and in a timely fashion. & $\begin{array}{l}\text { Positive cases must be communicated expediently to clinical team via } \\
\text { hospital alert system and Electronic Medical Records to facilitate timely } \\
\text { treatment and contact tracing. } \\
\text { Within laboratory department, a secure means of communication is } \\
\text { suggested, that is, TigerConnect. } \\
\text { Artificial intelligence to be considered in stratifying patients with } \\
\text { COVID-19. }\end{array}$ \\
\hline
\end{tabular}

COVID-19, coronavirus disease 2019; SARS-CoV-2, severe acute respiratory syndrome coronavirus 2.

This is in accordance with the Centers for Disease Control and Prevention as well as the WHO guidelines. ${ }^{10}$ By doing so, this practice allows containment of procedures that have the potential to generate aerosols and droplets. Examples of such activities typically include aliquoting or diluting samples, inoculation of bacterial culture media, nucleic acid extraction and chemical fixation of smears for microscopic analyses. Detailed nucleic acid extraction, quality control and rRT-PCR assays are beyond the scope of this article.

While the BSC is recommended, it is impractical to expect to perform all manual procedures here. A comprehensive risk assessment should be performed in order to review all areas in the laboratory which may be susceptible to transmission of infectious pathogens. In particular, we observed that operators in wet bench areas benefited from the use of a splash shield, and we further improved the interoperator communication for loading potential COVID-19 samples onto analysers. Following analyses and processing, we recommend that all surfaces, cryoboxes and equipment be cleaned with an appropriate disinfectant. The WHO recommends disinfectants with proven activity against enveloped viruses, such as sodium hypochlorite $0.1 \%$, a minimum of $62 \%-71 \%$ ethanol, $0.5 \%$ hydrogen peroxide ammonium or phenolic compounds. ${ }^{11}$ Our unit practises a decontamination protocol involving hypochlorite $10000 \mathrm{ppm}$ $(1 \%)$ solution in the event of spillage. Vigilance towards these protocols is of utmost importance as it has been shown by Ong and colleagues ${ }^{12}$ that air, surface environment and PPE are commonly contaminated by SARS-CoV-2.

\section{POSTANALYTICAL CONSIDERATIONS}

Following analyses, positive cases must be communicated urgently without delay to the ordering clinician. In our institution, we have deployed an automated healthcare messaging system, ${ }^{13}$ whereby critical results including COVID-19 are communicated real time to the physician, which reduces time to care for responding to this result. This will also be updated on the hospital's electronic medical record system, and the local epidemiology unit would be contacted so as to facilitate prompt contact tracing.

Within our department, we use a secure means of communication known as TigerConnect, which in our opinion is superior to alternative non-encrypted messaging platforms such as 'WhatsApp', which may breach patient confidentiality. We inform various laboratory professionals (ie, microbiology, clinical chemistry, haematology, molecular diagnostics) together with our Ministry of Health about the details and particulars of positive cases so as to facilitate an audit trail for sample processing and risk management.

Moving forward, we should leverage on artificial intelligence algorithms which potentially incorporate clinical features, laboratory results and radiological findings to identify and stratify patients with potential COVID-19. Some common laboratory indices, which are promising, include an elevated lactate dehydrogenase, prolonged prothrombin time and lymphopaenia. ${ }^{14} 15$ A drive towards developing a COVID-19 point-of-care rapid diagnostic kit would be ideal in the primary care setting and emergency departments, by reducing the 'needle-to-brain' time for clinical decision making and management.

\section{CONCLUSION}

Taken together, many questions remain for this emerging infection, but a collaborative global health effort will expedite our quest to effectively manage COVID-19. A summary (table 2) of laboratory considerations within the total testing process is included to highlight pertinent issues amidst an outbreak. Future efforts should revolve around novel biomarkers to stratify disease, trials on effective therapy and potential development of a vaccine. ${ }^{16}$ Adhering to biosafety regulations places tremendous stress on operational staff, but these measures reduce occupational health hazards and enhance a safe working environment in the laboratory. 


\section{Handling editor Tahir S Pillay.}

Contributors All authors have contributed equally to the intellectual design, critical appraisal and approval of the final manuscript.

Funding The authors have not declared a specific grant for this research from any funding agency in the public, commercial or not-for-profit sectors.

Competing interests None declared.

Patient consent for publication Not required.

Provenance and peer review Not commissioned; internally peer reviewed.

This article is made freely available for use in accordance with BMJ's website terms and conditions for the duration of the covid-19 pandemic or until otherwise determined by BMJ. You may use, download and print the article for any lawful, non-commercial purpose (including text and data mining) provided that all copyright notices and trade marks are retained.

\section{ORCID iD}

Shaun S Tan http://orcid.org/0000-0003-4100-0165

\section{REFERENCES}

1 Zhu N, Zhang D, Wang W, et al. A novel coronavirus from patients with pneumonia in China, 2019. N Engl J Med Overseas Ed 2020:382:727-33.

2 Lai C-C, Shih T-P, Ko W-C, et al. Severe acute respiratory syndrome coronavirus 2 (SARS-CoV-2) and coronavirus disease-2019 (COVID-19): the epidemic and the challenges. Int J Antimicrob Agents 2020:105924.

3 Li Q, Guan X, Wu P, et al. Early transmission dynamics in Wuhan, China, of novel coronavirus-infected pneumonia. N Engl J Med 2020. doi:10.1056/NEJMoa2001316. [Epub ahead of print: 29 Jan 2020].

4 Singapore Ministry of Health. Updates on COVID-19 local situation. Available: https:// www.moh.gov.sg/news-highlights/details/five-more-cases-discharged-four-newcases-of-covid-19-infection-confirmed [Accessed 18 Feb 2020].

5 Singh SR, Coker R, Vrijhoef HJ-M, et al. Mapping infectious disease Hospital surge threats to lessons learnt in Singapore: a systems analysis and development of a framework to inform how to DECIDE on planning and response strategies. BMC Health Serv Res 2017;17:622.
6 Singapore Ministry of Health. What do the different DORSCON levels mean. Available: https://www.gov.sg/article/what-do-the-different-dorscon-levels-mean [Accessed 19 Feb 20].

7 Lee VJ, Yap J, Cook AR, et al. Effectiveness of public health measures in mitigating pandemic influenza spread: a prospective sero-epidemiological cohort study. J Infect Dis 2010:202:1319-26.

8 World Health Organization. Laboratory testing for 2019 novel coronavirus (2019$\mathrm{nCoV}$ ) in suspected human cases. Available: https://www.who.int/publications-detail/ laboratory-testing-for-2019-novel-coronavirus-in-suspected-human-cases-20200117 [Accessed 03 Mar 2020].

9 World Health Organization. Guidance on regulations for the transport of infectious substances 2019-2020. Geneva: World Health Organization, 2019(WHO/WHE/ CPI/2019.20).

10 Centers for Disease Control and Prevention. Interim laboratory biosafety guidelines for handling and processing specimens associated with coronavirus disease 2019 (COVID-19). Available: https://www.cdc.gov/coronavirus/2019-ncov/lab/lab-biosafetyguidelines.html [Accessed 02 Mar 20].

11 World Health Organization. Laboratory biosafety guidance related to the novel coronavirus (2019-nCoV), 2020. Available: https://www.who.int/docs/defaultsource/coronaviruse/laboratory-biosafety-novel-coronavirus-version-1-1.pdf?sfvrsn= 912a9847_2 [Accessed 01 Mar 2020].

12 Ong SWX, Tan YK, Chia PY, et al. Air, surface environmental, and personal protective equipment contamination by severe acute respiratory syndrome coronavirus 2 (SARSCoV-2) from a symptomatic patient. JAMA 2020.

13 Ti LK, Ang SBL, Saw S, et al. Innovative strategy for effective critical laboratory result management: end-to-end process using automation and manual call centre. BMJ Qual Saf 2012;21:657-62.

14 Chung M, Bernheim A, Mei X, et al. CT imaging features of 2019 novel coronavirus (2019-nCoV). Radiology 2020:200230.

15 Wang D, Hu B, Hu C, et al. Clinical characteristics of 138 hospitalized patients with 2019 novel coronavirus-infected pneumonia in Wuhan, China. JAMA 2020. doi:10.1001/jama.2020.1585. [Epub ahead of print: 07 Feb 2020].

16 Wong JEL, Leo YS, Tan CC. COVID-19 in Singapore-Current experience: critical global issues that require attention and action. JAMA 2020. doi:10.1001/jama.2020.2467. [Epub ahead of print: 20 Feb 2020] 